\title{
Hybrid Design Tools for Participatory, Embodied Sensemaking: An Applied Framework
}

\author{
Dorothé Smit \\ dorothe.smit@plus.ac.at \\ University of Salzburg \\ Salzburg, Austria \\ Martin Murer \\ martin.murer@plus.ac.at \\ University of Salzburg \\ Salzburg, Austria
}

\author{
Bart Hengeveld \\ b.j.hengeveld@tue.nl \\ Eindhoven University of Technology \\ Eindhoven, The Netherlands \\ Manfred Tscheligi \\ manfred.tscheligi@plus.ac.at \\ University of Salzburg \& AIT Austrian Institute of \\ Technology \\ Salzburg, Austria
}

\begin{abstract}
In design, we often deal with complex problems that require participatory, embodied sensemaking to solve. There are abundant design tools available - both physical and digital - to support these activities. While digital tools have continued to gain presence in the design processes over the last decades, due to, e.g., widened availability, improved flexibility, and the potential to increase productivity, physical tools and analogue practices still hold a solid place in the design process for many designers. To bridge the gap between the physical and digital, and to benefit from the best of both worlds in tools for design, hybrid tools are being developed. This paper aims to identify design opportunities for future hybrid design tools, by exploring the characteristics of designing for participatory, embodied sensemaking, in the context of physical, digital, and hybrid tools.
\end{abstract}

\section{CCS CONCEPTS}

-Human-centered computing $\rightarrow$ Systems and tools for interaction design.

\section{KEYWORDS}

physical-digital hybrids, tools for design, framework, participatory embodied sensemaking

\section{ACM Reference Format:}

Dorothé Smit, Bart Hengeveld, Martin Murer, and Manfred Tscheligi. 2022. Hybrid Design Tools for Participatory, Embodied Sensemaking: An Applied Framework. In Sixteenth International Conference on Tangible, Embedded, and Embodied Interaction (TEI '22), February 13-16, 2022, Daejeon, Republic of Korea. ACM, New York, NY, USA, 10 pages. https://doi.org/10.1145/3490149. 3501332

Permission to make digital or hard copies of all or part of this work for personal or classroom use is granted without fee provided that copies are not made or distributed for profit or commercial advantage and that copies bear this notice and the full citation on the first page. Copyrights for components of this work owned by others than the author(s) must be honored. Abstracting with credit is permitted. To copy otherwise, or republish, to post on servers or to redistribute to lists, requires prior specific permission and/or a fee. Request permissions from permissions@acm.org.

TEI '22, February 13-16, 2022, Daejeon, Republic of Korea

(C) 2022 Copyright held by the owner/author(s). Publication rights licensed to ACM. ACM ISBN 978-1-4503-9147-4/22/02 . \$ \$15.00

https://doi.org/10.1145/3490149.3501332

\section{INTRODUCTION}

The act of designing is a process that is becoming increasingly involved, not in the least due to rapid technological advances that influence what is being designed, and how it can be designed. Especially in the early stages of design processes, designers (often collaboratively) try to make sense of complex information to make the right design decisions. In this process, many tools - both physical and digital - are used. Design tools can help advance the creative process and streamline collaborative efforts, and in this way, improve the quality of design outcomes. Physical and digital tools both have respective advantages and disadvantages when used in design processes, related to e.g., their usability, shareability, archivability, tangibility, and reproducibility, and a large research field in $\mathrm{HCI}$ and Design is dedicated to the development of novel tools to support design processes $[26,46]$.

$\mathrm{HCI}$ and design research has also recently displayed increased interest in digital-physical hybrids - artefacts that blend the physical with the digital - in various HCI subfields [62]. As more and more of our interactions with artefacts in the world are supported by digital technology, designers and researchers are attempting to merge digital and physical materials into an outcome that is greater than the sum of its parts [13]. This is no different in the development of tools for design: many design researchers are preoccupied with the development of hybrid design tools [22]. The goal for these tools is to combine the best characteristics of physical design tools with the best characteristics of digital design tools, to create new tools that are suitable to support design processes that include rapidly developing technologies. And while this field is quickly expanding with practical examples, there does not seem to be a consolidated framework that describes how to successfully create hybrid tools for design.

In this paper, we establish the importance of design tools that support sensemaking, in particular, participatory, embodied sensemaking. By applying a framework of characteristics to design for participatory, embodied sensemaking to physical and digital tools in general, and two particular cases of hybrid tools for design, we demonstrate how hybrid design tools can support participatory, embodied sensemaking in design processes. We then discuss four lessons learned from applying the framework to the two hybrid design tools, and how better hybrid tools for participatory, embodied sensemaking in design processes, can be designed. Finally, we 
reflect on the use of this particular framework, and how it can be further developed in future work.

\section{THEORETICAL FRAMING}

In the following section, we will outline the theory of participatory, embodied sensemaking, and how this relates to the practice of design. We also describe a framework to characterize tools that support embodied sensemaking, which we will then apply to physical, digital and hybrid design tools.

\subsection{Participatory Embodied Sensemaking}

Human beings are constantly engaged in sensemaking processes: as our reality changes across time and space, sensemaking - the continuous effort to understand the connections among people, places and things [35] - is a continuous activity, related to the self, culture, society and organization [12]. Through sensemaking processes, we make meaning of our context [10]: our environment, the people who take part in it, and the things that are situated in it [56]. Sensemaking is therefore always embodied: we perceive the world by physically interacting with it [25], we make sense of the complexity around us by doing things [36, p. 11, emphasis in original].

In the field of human-computer interaction and embodied interaction, sensemaking has garnered attention (see, e.g., [1, 25, 28, $43,45,59,68,71]$ ), and different terms to describe the activity of sensemaking with others have been used: collaborative sensemaking (e.g., [43, 59, 68]; embodied sensemaking (e.g., [25, 52, 60, 63]; and participatory sensemaking (e.g., $[8,10,28]$ ). Many of the aforementioned publications share a significant theoretical overlap in the definition of sensemaking as a situated activity that is achieved by being in (and interacting with) the world $[8,63]$.

In an attempt to further bridge these terms, in this paper, we describe the activity of establishing intersubjectivity as participatory, embodied sensemaking. Embodied sensemaking is, indeed, not something that happens passively. It is an activity that is contextually participatory: it requires participation, from the human actor that attempts to make sense, in the environment that they find themselves in [25]. Embodied sensemaking is also socially participatory [10]. By engaging in embodied sensemaking activities in social situations, we can participate in each other's sensemaking processes, and together establish shared meaning, or intersubjectivity [9].

\subsection{Design is Making Sense}

As established, humans are continuously engaged in participatory embodied sensemaking. When we engage in design activities, this is no different. However, design activities can be distinguished from other sensemaking activities, as design problems are often 'wicked' problems [4], for which no clear solution is immediately visible. Klaus Krippendorff describes sensemaking as a "circular cognitive process" [37, p. 13], starting from a 'fuzzy image'. From this fuzzy image, or the 'initially incomprehensible situation', the designer partakes in a hermeneutic circle during which meanings are constructed until a 'sufficient coherent understanding' evolves. Krippendorff posits that form and meaning are intricately related: "Something must have form to be seen, but must make sense to be understood and used." (ibid, p. 14). The designer's form-giving practices must, therefore, follow her sensemaking practices.

This line of thought has been further explored: Verganti writes that design can be seen as "the action that aims at innovating the meaning [...] of products" [67, p. 452]. The handling, shaping, and interaction with various materials supports the creation of meaning [21, p. 1]. Through sensemaking activities, designers give meaning to the products, systems and services they create [67].

Others have described design practices in similar ways, though not using the same terminology of sensemaking and the creation of meaning. Donald Schön [49] defined design as a "reflective conversation with the situation" (p. 76), highlighting the two-way relation-ship between designer and situation. The designer deals with complex processes, and sometimes her actions produce unintended consequences: the situation 'talks back' (ibid, p.79). From this reflexive conversation, the designer "may take account of the unintended changes [...] by forming new appreciations and understandings" (ibid, p. 79). This definition of designing closely relates to the definition of sensemaking practice by De Jaegher and Di Paolo, who describe sensemaking as an "exchange with the world" [10, p. 488]. Nigel Cross [6] ascribes designers' particular 'ways of knowing' to the positioning of the field between discipline and science, and describes that - through the practice of, e.g., sketching - designers relate what they know about the design problem to what they know about the solution. Designers use these tools to "explore and resolve their thoughts" (ibid, p.38): to make sense of a problem space and create understanding. In their sensemaking practices, designers are embedded in a relationship with the users of the artefacts that they design.

\subsection{Characteristics of Tools that Support Sensemaking}

With the many definitions of sensemaking practices within $\mathrm{HCI}$ and design, come many descriptions of the characteristics of tools that support participatory, embodied sensemaking. The terminology in this field is broad, and some terms defined by researchers in the field of interaction design overlap with terms defined by researchers in the field of cognitive science, psychology, philosophy, and organizational science. We found, however, that by taking a higher level of abstraction, many of the terms described by these authors can be captured in the four design characteristics for 'embodied-inspired design' for participatory sensemaking as defined by Jaasma [27, p. 205]: tangibility, commonality, visual representation, and ambiguity. We have therefore chosen this categorization as a starting framework for our research into physical-digital hybrid tools for design. However, we have chosen to supplement Jaasma's characteristics with additional terms used in other literature on participatory, embodied sensemaking; creative processes; and cognitive science; to more precisely define the nature of these characteristics.

Tangibility: A tool that is tangible is a tool that is touchable, often literally graspable, and has physical material properties. The characteristic of tangibility can be considered to include, e.g., the concepts of boundary objects as 'things to think with' [2]; scaffolds $[5,25,64]$ : physical 'things' that can be specific to a certain task, 
but can also be 'ad hoc recruited props' [62] and engagement catalysts [25]: tools that invite bodily, skilful interaction and thereby contribute to creativity [30].

Commonality: The commonality of a tool relates to the rate with which individual understandings of participants overlap and are 'owned' by each participant. This characteristic is described similarly to Jaasma's definition by Eris et al., [15]. Related to this characteristic is the dialogical system between participants [25, 53]: the idea that when participants work towards a common goal, they first need to achieve social coordination [53], and social situatedness [25]: developing intersubjectivity is embedded in the socially (and culturally) situated environment [39].

Visual Representation: Visual representations are containers of information. These representations are the means by which insights is communicated between participants [28]. This category can be considered to include, e.g., the concepts of traces [25, 61]: the visual and physical materials that are created during and left behind after a creative process; or (informational and transformational) externalization [2,14]: embodied representations of our thoughts. These representations can be both two-dimensional and three-dimensional.

Ambiguity: Ambiguity in a design process allows for "freedom of interpretation" [27, p. 205] and, perhaps more importantly, openness to more than one interpretation. It invites people to give meaning to the situation at hand from their own first-person perspective [25], where interactive imagery $[19,25]$ allows for freedom of interpretation and confusion that designers need to develop into a plausible narrative [47].

Through the lens of these four categories, and the concepts that we have included in each category, we will turn towards tools for design: physical tools, digital tools, and hybrid tools, and investigate in which ways they support or even invoke tangibility, visual representations, commonality, and ambiguity. We discuss the advantages and disadvantages of fully digital and fully physical tools in the context of participatory, embodied sensemaking, and investigate two cases of existing hybrid tools through the lens of designing for participatory, embodied sensemaking. With this paper, we contribute to the discourse on hybrid materiality in design practice.

\section{TOOLS FOR THE EARLY STAGES OF THE DESIGN PROCESS}

Design is a broad practice that includes many activities. The goal of this research is to investigate the effect of hybrid tools on participatory embodied sensemaking in design. Therefore, we have limited the scope of this research to tools that support the 'fuzzy front-end' of design, since this stage of the design process includes the pre-design phase, during which open-ended questions about the experience to be designed are explored [48]. During this stage, designers aim to move from ambiguity and uncertainty to more concrete and focused design goals [32] by means of collecting and sharing inspiration, knowledge and opportunities [38], defining goals [66], generating ideas and developing initial concepts [23]. These activities are often collaborative activities that take place before the 'actual' design work begins [44].
In these collaborative activities, different stakeholders with different backgrounds are often involved [41]. At the same time, these activities are characterized by ambiguity, vagueness, open-endedness, and uncertainty [44]. Effective participatory sensemaking therefore plays a major role in the successful completion of the early stages of the design process.

The use of tools is ubiquitous in design practice [7, 55], and the definition of what a 'design tool' can be is broad: methods, techniques, approaches, and practical tools are all often characterized as design tools [54]. We specifically look at the types of tools that support and extend cognitive systems and abilities of the designer [26] in the early design stages, such as creativity support tools that can structure the early ideation stages in a design process, or tools that are used to support collaboration.

Over the past few decades, products, services and systems have become increasingly digitally connected, and as a result of that, the design space that designers engage with becomes a blend of the physical and the digital [11]. Digital design tools, rapid prototyping machinery and physical computing developments have become integral parts of the design process [3]. Nevertheless, a majority of designers still also make use of analogue or physical tools for design, preferring to sketch with pen and paper [55] or using tools such as card decks for the ideating stages [17].

In the next sections, we discuss physical and digital tools in relation to the characteristics to design for participatory, embodied sensemaking. Although we contrast physical and digital tools, our goal is not to claim that one type of tool is better than the otherrather, we want to highlight the strengths and weaknesses of either type of tool in the context of participatory, embodied sensemaking in design processes.

\subsection{Physical Tools for Design}

For as long as people have been designing, engineering, and building things, physical tools have played a role in the process. There is nothing quite as straightforward as simply putting pencil to paper to just start sketching. Other physical tools for design have also found a fixed place in the early stages of the design process: e.g., post-its, whiteboards, card sets, tinkering kits, ideation toolkits, and games [46]. In our categorization of physical and digital tools, we consider physical tools those that have physical properties, but no computational properties.

In relation to the first characteristic to design for participatory, embodied sensemaking, tangibility is a key characteristic of physical tools for design, especially in comparison to digital tools. Tangible objects have been shown to better support epistemic action than non-physical tools [34, 42]: physical objects can become 'shareable objects of thought' [33], which support participatory, embodied sensemaking.

The tangibility of physical tools directly relates to the commonality of physical tools: the tools are directly available to all participants (rather than, e.g., in a situation where a mouse, keyboard or touch screen is being used in a collocated setting). Physical tools invite dialogical systems between participants, allowing participants to coordinate, co-regulate, and co-adapt their actions more easily than with fully digital tools [25]. The space that tangible tools take up - e.g., many of them are used with participants positioned 
around a shared surface - also aids the social situatedness of participants, in contrast to collocated participants who are directed to a screen when using a digital tool.

People are unable to achieve the same granularity or detail with physical tools, as they are with digital tools. Physical tools therefore leave more up for interpretation: there is a greater ambiguity when working with physical design tools, than working with digital design tools. This openness to interpretation, which can sometimes even result in confusion between participants, leads to "seeing something as something else" [19, p. 164], an essential quality of creative work.

Finally, physical tools naturally leave visual representations of the work done in the form of traces: the externalizations of participants during the design process in the form of, e.g., sketches, Post-It notes, design cards, are visible in the space throughout the duration of a design session. This allows participants to refer 'back' to certain steps in the creative process, to develop ideas that are 'out there' and to combine ideas [28].

Nevertheless, physical design tools have limitations. People are unable to be as precise with physical tools as they can be with digital tools, and therefore physical tools can be less suited for design tasks in which precision or high fidelity is essential. It can be hard to reproduce analogue outcomes of design activities performed with physical tools (as anyone who has ever had to archive the outcomes of a paper-based brainstorm can attest to). This also limits the shareability and searchability of the design outcomes. Relatedly, the vast majority of physical tools for design only work optimally when the participants in the design activity are collocated.

\subsection{Digital Tools for Design}

To counter some of the problems of physical design tools, to accommodate the increasingly digital nature of most products, systems and services designed nowadays, as well as simply due to the ubiquitous access to computers, digital tools for design have become commonplace in the design process. We consider digital tools for design any tool of which the funtion hinges on computational aspects. These tools often (though not always) have graphical user interfaces through whichs users interact with the tool.

Especially now that more of our work is performed in a dislocated, asynchronous way, digital tools solve the problem of shareability. Further, design outcomes created with digital tools often have better searchability, making it easier to archive design tasks and extending the 'shelf-life' and reusability of the outcomes of a design activity. Additionally, fully digital tools make it easier to collaborate with participants that are not collocated: especially online digital systems provide options for synchronous and asynchronous dislocated collaboration.

However, where digital tools can solve some of the issues that the use of physical tools bring, opposite and additional issues can be seen as well.

The lack of tangibility of digital tools can make it more difficult to 'grasp' complex design ideas [16]. Digital design tools can also make things seem possible or buildable, when they are, in fact, physically impossible. In relation to collaboration, physical tools make it easier than digital tools to divide design areas into personal spaces, and collaborative spaces [40], which can improve participatory, embodied sensemaking [51].

Furthermore, digital tools offer a completely different type of commonality than physical tools, if commonality is present at all. We have previously described how digital tools often have a single 'point of access', such as a mouse, keyboard, or touch screen, which makes it hard for all participants to collaborate as equals. The digital design product is generally also 'owned' by a single person: somebody created the digital file, saved it in their cloud, or is running it from their laptop. Contrast this, for example, to a wall filled with Post-Its created by many team members: there is no single 'owner' of the Post-It wall. Nevertheless, some digital design products (drawings, visuals, documents) may also have increased commonality over analogue design products: one could imagine adding content to a shared digital document, but might hesitate to scribble something on a piece of paper that somebody else is still working on. In terms of the social situatedness of digital tools, the context and environment of the user and the tool are less relevant: a digital tool works the same in Stockholm, as it does in Shanghai.

While digital design tools allow their users to be more precise, in the fuzzy front-end of the design process, they offer an unnecessarily high level of granularity [16], making designers focus on a 'final' product, rather than the improvisational, iterative nature of the early design stages [22]. While digital tools can reduce human errors, they often also lessen ambiguity, by reducing, or removing entirely, unintended outcomes of a design process [72]. The use of digital tools renders the first-person-perspective into 'everyone's-perspective', offering a pretence of objective truth to its users. Where a sketch, a Post-It, or a scribbled note can often transform and be reinterpreted throughout a design process - a vital element in design explorations [31] - a digital drawing made in a CAD program stays what it is.

The characteristic of visual representation is the only characteristic that is strongly supported by digital tools: most, if not all, digital tools for design are based on graphical user interfaces, supporting visual representations in myriad formats, including formats that physical tools don't support (e.g., moving imagery, video, audio). Due to the ease with which digital files can be copied, and the use of versioning in many software programs, digital design tools can also support the concept of traces [65]: different versions of files can show the process of how participants came to a certain design decision or idea. Unlike with physical tools, however, these traces are often hidden from participants and can only be viewed by, e.g., using the undo/redo functionality of a program, or using the 'history'-panel if available.

\subsection{Hybrid Tools for Design}

Why, then, would we need hybrid tools? Why don't we simply stick with the physical tools that we have, and move to digital tools when we arrive at that point in the design process where they are necessary? When we talk about hybridity in design tools, we intend to describe the merging of physical and digital tools [18] in a way that goes beyond the individual categories of the physical and the digital. Hybrids challenge the division between digital information and physical objects [62], and rather weave them together. The aim 
of these hybrid tools is to realize a potential that is greater than the sum of its digital and physical parts [13].

The need for digital-physical hybrid tools can be illustrated by the finding that neither fully physical tools, nor fully digital tools, meet the needs of designers that concern themselves with interconnected products, services and systems. In many design cases, physical creation takes place without the support of any digital products, whereas the digital phase is fully executed on computers. Closer integration of the digital and the physical in the design process may be an important requirement for hybrid design [20].

It makes sense, then, that over the last decade or so, many designers have developed tools for design along the hybrid spectrum, ranging from mostly physical to mostly digital, that attempt to combine the best of both the physical and the digital world. As this field is rapidly expanding, it is worth investigating these tools from the perspective of participatory, embodied sensemaking, to better understand how these tools work.

\section{APPLYING THE FRAMEWORK TO TWO CASES}

In the next sections, we will be examining two cases of our own previous work about physical-digital hybrid tools, from the perspective of designing for participatory, embodied sensemaking. We will describe how the four characteristics to design for participatory, embodied sensemaking were translated into design elements in the two cases, but also where the prototypes may have missed the mark. Based on these cases, we will then discuss opportunities and challenges for designing physical-digital hybrid tools to design for participatory, embodied sensemaking. The first case, MacroScope, was analyzed based on observations of the use of the tool in an HCI research center (for details see [50]). The second case, \#CapIt, was analyzed based on photo elicitation-supported interviews conducted with three 'power users' of the system (for details see [51])

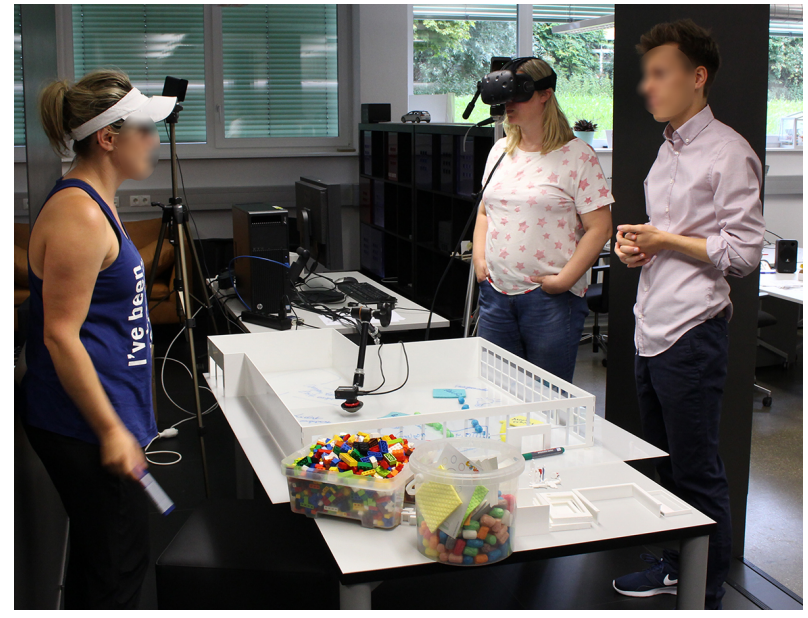

Figure 1: MacroScope combined a $360^{\circ}$ camera and a virtual reality headset with a physical scale model, to give participants an immersive, first-person perspective of the scale model.

\subsection{Case One: MacroScope}

MacroScope is a tool that uses a $360^{\circ}$ camera and a virtual reality headset to give participants a first-person perspective on scale models (see figure 1). As one participant wears the headset and gains a first-person perspective, the other participants maintain a bird's eye view. The scale model that accompanied this setup was designed to function as a 3D whiteboard, meaning that participants could write on surfaces. Furthermore, the scale model was often outfitted with materials for open-ended design, such as LEGO ${ }^{\text {TM }}$, Play-Doh, cardboard and paper. The tool was used in the multistakeholder redesign of a large space.

Tangibility: MacroScope was designed to invite playfulness from multiple stakeholders by using a familiar modality - writing on a whiteboard - as an engagement catalyst. This encouraged even stakeholders completely unfamiliar with creative processes to participate with an activity they already knew how to do. The scale model also invited the use of boundary objects, or things to think with. While using MacroScope, we noticed that even the more 'prescriptive' boundary objects, such as miniature furniture, invited exploration. Participants would combine the miniature furniture pieces with LEGO ${ }^{\mathrm{TM}}$, Play-Doh, or pieces of cardboard as scaffolds for their design ideas. Non-immersed participants would often change something in the scale model - adding objects, moving walls, or even moving the $360^{\circ}$ camera, and ask the participant immersed in the first-person perspective to give their opinion on the changes. Nevertheless, there was a great mismatch between the immersed person and their bodily skills: simple actions, such as grabbing an object and moving it around the scale model, needed to be relearned from this perspective.

Commonality: The immersed perspective on the scale model was very strongly owned by the person immersed in the $360^{\circ}$-view. At the same time, there was a strong bond of social situatedness among the other participants, often creating a split between the immersed participant, and the participants who were not immersed. The dialogical system between all participants therefore needed to be renegotiated at the beginning of a creative session, and throughout the session. This renegotiation of the dialogical system often led to surprising findings and new understandings between the participants. It was much easier to renegotiate the dialogical system, once all participants had at least experienced the first-person perspective via the head-mounted device.

Visual Representation: the physical modalities of the scale model invited participants to externalize their thoughts in the form of traces. Using whiteboard markers, participants drew arrows to indicate, e.g., customer flow, made notes on the floors and walls, or sketched out floor plans. The other materials used in the scale model, such as miniature furniture, $\mathrm{LEGO}^{\mathrm{TM}}$, and cardboard creations, helped participants recall design conversations and decisions even long after the design activity had ended. Participants also often used the virtual $360^{\circ}$ view to inspect the results of their actions from the first-person perspective. However, this perspective leaves no enduring traces: when the system is turned off at the end of the session, the only visual representation of the first-person perspective is the presence and the position of the $360^{\circ}$ camera: the perspective itself is not available any more. 


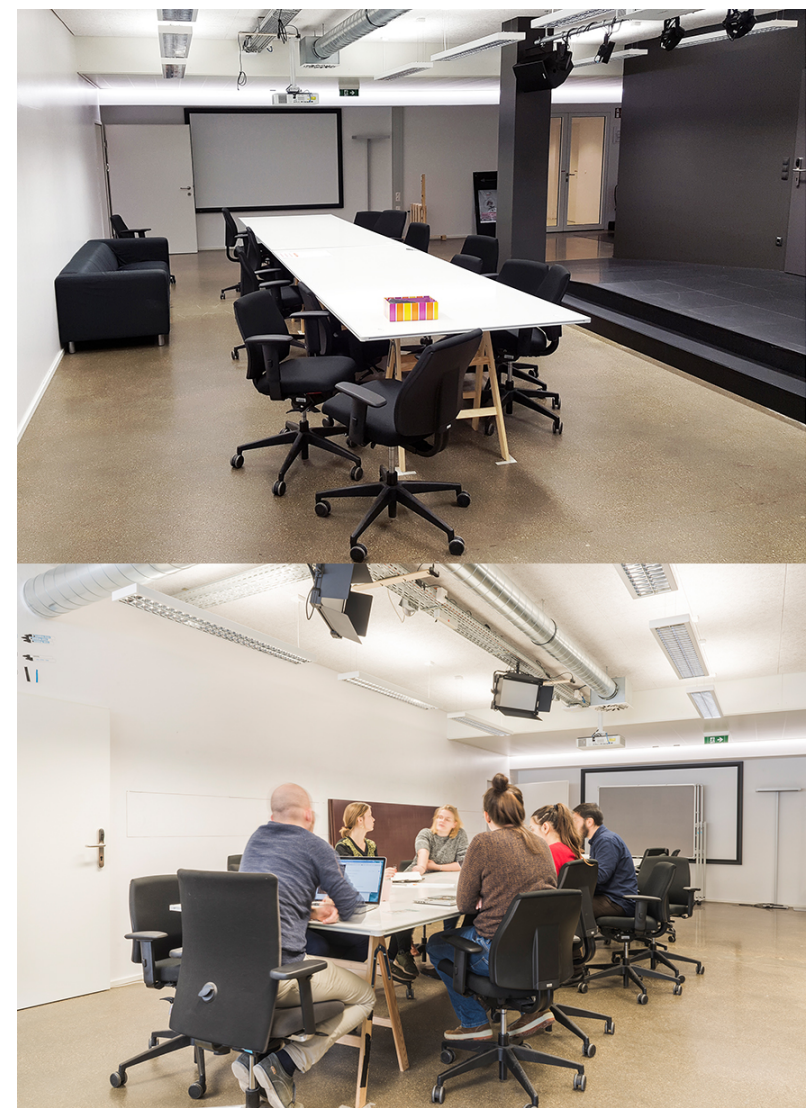

Figure 2: The whiteboard table seen in this figure is a popular location for collaborative meetings. Above the table, two $4 \mathrm{~K}$ cameras are suspended. When users of the table hit a Bluetooth button on the table, those cameras take a snapshot that is sent to the workplace's internal messaging system.

Ambiguity: The MacroScope system was designed to literally offer a first-person perspective immersed in physical scale models, offering a way to 'see something as something else' and create a plausible narrative of design, based on that perspective. This mix of perspectives - the analogue bird's eye perspective and the digital first-person perspective - left much room for ambiguity: participants had to imagine the other's perspective as they were negotiating their own perspectives on the scale model.

\subsection{Case Two: \#CapIt}

\#CapIt is a system that takes snapshots of the notes and sketches made on a horizontal whiteboard that also functions as a table (see figure 2). The snapshots are automatically uploaded to a channel in the internal messaging system, where they are available to anyone who has access to the messaging system. The whiteboard table and its capture system are used regularly for, e.g., collaborative ideation sessions, team meetings, and project progress updates. The system was designed to solve the problem of archiving whiteboard traces and creative sessions around tables in a transparent way.
Tangibility: The horizontal whiteboard table that is part of the \#CapIt system aims to combine the benefits of using whiteboards in creative sessions, such as ease of use, and combine it with the benefits of collaborative work around a table, such as the ability to use physical materials on the horizontal surface. As with the scale model, the familiar modalities of the whiteboard immediately invite sketching and doodling, catalyzing the engagement of those using the whiteboard table. We also notice that users of the \#CapIt system often bring materials to the table to design with or to think with (see figure 3): these can be considered boundary objects or scaffolds for design. Furthermore, users of the system have reported using the captures of the whiteboard table themselves as things to think with: by downloading the captures to their personal computers to continue brainstorming, or by printing a capture and sketching on top of it.

Commonality: analogue whiteboards have long been a popular tool used in many collaborative work settings. While whiteboards are easy to use and reuse for all participants, it is usually only one, or maximum two, participants who can actively interact with the whiteboard at the same time: if more participants would interact at the same time, the whiteboard would become crowded and overview would be lost. The horizontal whiteboard table that is part of the \#CapIt system solves this problem by offering a point of access to the whiteboard by everyone sitting at the table: every participant has the ability to contribute to the shared space without needing to renegotiate the dialogical system. Furthermore, the ability to take a photo of the whiteboard table by pressing a Bluetooth enabled button that always lies on the table, allows each participant to take charge of capturing and documenting the session. Those captures are then shared in the messaging system, that each participant has access to: no single participant has ownership of the captures taken.

Visual Representation: The \#CapIt system allows for several forms of externalization. First and foremost, as with all whiteboards, people can scribble, draw, and doodle without reservation on the table. There is no need to worry about running out of space: if the table is full, simply capture your work and clear some space. We also noticed users who participated in long creative sessions using the \#CapIt system in a time-lapse-like manner, taking intermittent captures of their work. These captures form traces for the users, allowing them to reconstruct their trains of thought after a creative session has ended.

Ambiguity: analogue whiteboards allow for more ambiguity and freedom of interpretation than, for example, digi-boards or physical whiteboards. Due to the different first-person perspectives of the users sitting around the table, the whiteboard table invites participants to add onto the contributions of others. This enables participants to see their own contributions as something else, through the perspective of another.

\section{DISCUSSION}

In the previous sections, we have introduced the four characteristics to design for participatory, embodied sensemaking in the context of digital-physical hybrid tools for design. Through the application of these four characteristics to two cases, we have demonstrated how hybrid design tools can support, but also impair, efforts in participatory, embodied sensemaking towards shared meaning. In 


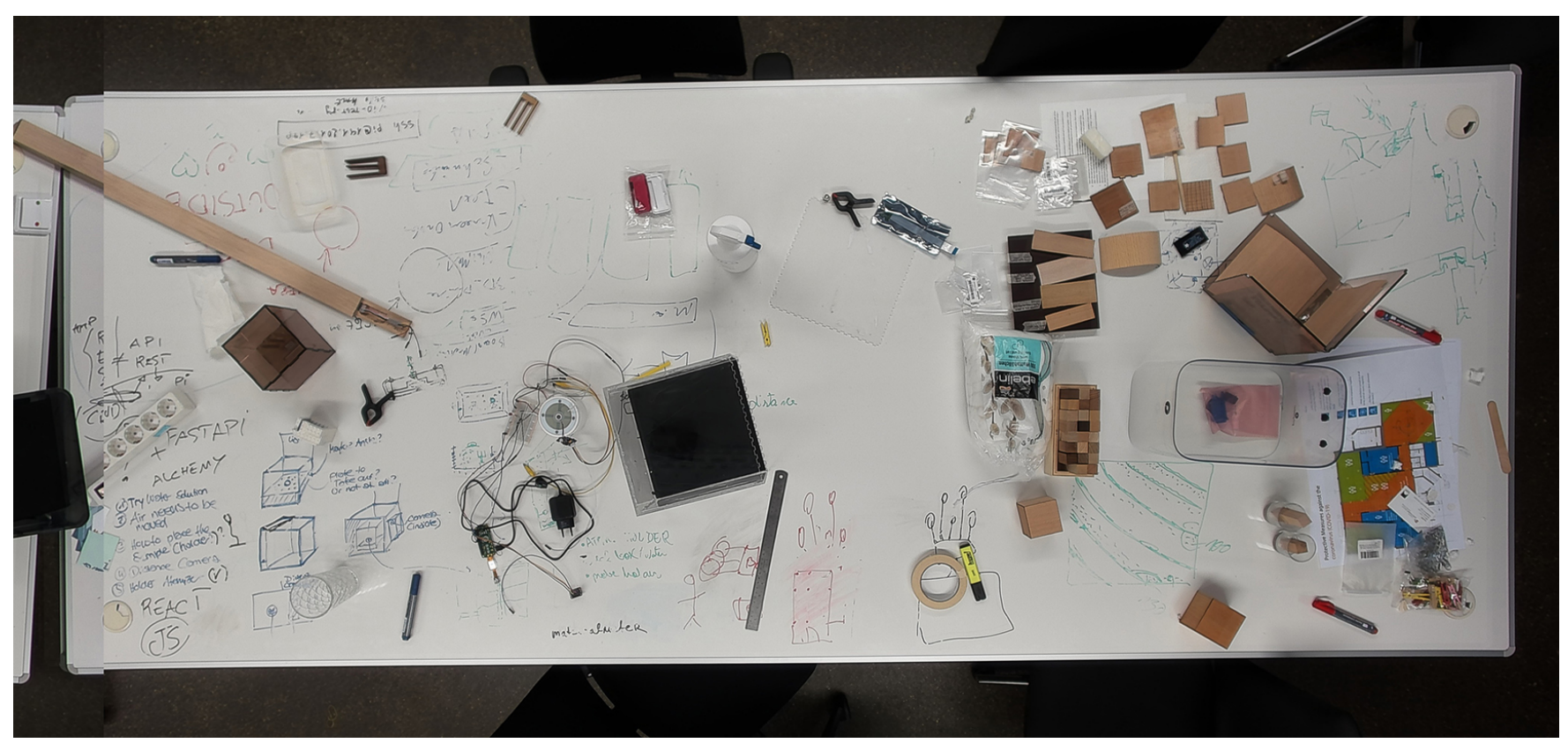

Figure 3: Participants often bring tangible materials to the \#CapIt whiteboard table during creative sessions, and combine notes and sketches on the whiteboard with these objects.

the next sessions, we will discuss lessons learned from these cases, and share suggestions for the design of hybrid tools that support participatory, embodied sensemaking in the early stages of a design process. Furthermore, we reflect on the categorization of the characteristics to design hybrid tools for participatory, embodied sensemaking.

\subsection{Embedding Hybridity}

As discussed previously, hybrid tools are bridges built between the digital and the physical, with the aim of realizing a potential that is greater than the sum of its parts [13]. To achieve this goal, however, hybridity cannot simply be achieved by adding a digital layer to a physical tool, or adding a physical layer to a digital tool. If the hybrid bridge between the physical and the digital is not implemented properly, the possibility exists that the connection between the physical and digital is lost completely. This can cause issues in sensemaking between participants interacting with different parts of the tool, leading to the need to constantly renegotiate the dialogical system between participants who are engaged with the physical, and participants who are engaged with the digital. We have noticed this in the deployment of MacroScope, where the bridge between the digital and physical was not pronounced enough. This led to the immersed participant to be socially situated in a such a differing way from other participants, that commonality could not be achieved. A succesful example of the embedding of hybridity from the beginning stages of developing a hybrid design tool, is the project Codable Objects by Jacobs \& Buechley [29], which aimed at a "simple workflow from software to fabrication to facilitate the transition from programming to physical output".
In the design of hybrid tools, designers must aim to embed hybridity from the first design steps, and consider the impact of the digital and physical parts of their tools on the design process.

\subsection{A Two-Way Street}

The more common way to achieve hybrid design tools seems to be to take an analogue tool as a starting point, and investigate how this tool can be improved with a digital layer, resulting in a hybrid tool. This may be due to the nature in which design tools have been developed over the last decades (becoming increasingly digital from a physical starting point), and deployed in design processes (the fuzzy front-end of design is often done with physical tools, whereas later stages of design are performed using digital tools). We want to emphasize that hybridity is a two-way street, and considering opportunities for hybridity starting from the perspective of digital tools is a promising venue. An excellent example of this is SPATA [69]: a project developed from the starting point of computer-aided design (CAD). The tools developed by Weichel et al. (calipers and a protractor) help designers get a 'grip' on the real dimensions of their digital drawings, preventing surprises when designs go to production. The SPATA tools become the boundary objects that bridge the physical and the digital. Instead of departing from an analogue of physical tool to design a hybrid tool we encourage designers to consider fully-digital tools as a starting point for hybridity. This could invite more ambiguity and tangibility into design processes that have become formalized by digital tools.

\subsection{Without a (Digital) Trace}

Previously, we have considered the importance of visual representation for participatory, embodied sensemaking, and discussed the 
opportunities of digital tools to create versatile externalizations of design processes. In both the MacroScope and the \#CapIt case, it became clear how important both the visibility of chronology, and the long-term visibility of traces are for sensemaking processes. When creating a hybrid design tool that enables digital externalizations, it is vital to consider the visual representation of the temporal aspect of the creation of the traces, as knowledge about the order in which traces are created can support sensemaking practices of participants. An example of combining physical traces with the power of digital versioning is demonstrated in the Hybrid Machine developed by Wendrich [70], with which captures of a horizontal, physical work surface can be combined into a 'merged stack' to visualize collaborative design iterations. Further, if a hybrid tool relies on digital traces, designers should consider how to make those traces visible over a longer period of time, even after an activity has ended (and the hybrid tool might be 'turned off'), much like post-its on a wall would be visible even after an activity has ended, which supports further, individual, reflections on the activities [61]

\subsection{Skilful Bodily Interaction}

An important condition for participatory, embodied sensemaking is the engagement of the participants involved in the activity. However, engagement can be catalyzed [57]. Engagement catalyzers are often tangible, and rely on bodily skills for interaction [52], because our bodily skills open up new perceptions of the world and transform our understanding of the world itself [58]. An example of a hybrid tool that invites the use of bodily skills is the Embodied Encounters Studio by Hummels [24], which invites participants to explore concepts hands-on, in an informal, playful, and engaging setting. We have noticed, especially in our explorations with MacroScope, that a hybrid tool that limits participants' use of their bodily skills, or requires them to relearn how to use their bodily skills while using a hybrid tool, quickly quells their engagement with the activity at hand. As a result, the participant immersed in the first-person perspective via the virtual reality headset would become an observer, rather than an active participant in the creative session. In the case of MacroScope, the completely new perspective on the design problem initially provided refreshing inputs from the immersed participants, but ultimately, the mismatch between bodily skills and perspective, and the difficulty relearning these skills, caused strong disengagement over time. With this example, we want to illustrate that in the design of hybrid tools, a careful balance should be struck: while it might be worth to (temporarily) constrain or amend the bodily skills of participants to elicit new points of view, a too strong or too long inhibition can result in disengagement. Designers should actively construct the bridge between the physical and the digital in such a way that participants can rely on bodily skills to act as engagement catalyzers in the use of the hybrid tool.

\section{CONCLUSION \& FUTURE WORK}

As hybrid forms of technology, using new types of materiality, become more and more embroidered into the fabric of our daily lives, the tools we use to design these technologies need to evolve as much as the technologies do. In this paper, we have discussed the importance of creating physical-digital hybrid tools for design that support participatory, embodied sensemaking. We have theoretically expanded an existing framework, and used this framework to review two cases of hybrid tools for design, with the aim of illustrating the practical application of the characteristics in the framework in the design of hybrid tools. Based on this application, we offered lessons learned from the cases and discuss the implications for the design of hybrid tools that support participatory, embodied sensemaking. With this paper, we contribute to the discourse around hybrid materiality, as well as the rich research field around tools for creativity and design.

Finally, we would like to reflect on our use of the framework, which includes the four categories as defined by Jaasma [27], and the terms that we have subordinated in each of these four categories. As previously mentioned, these four characteristics are broad, and each characteristic covers several terms described in other literature. As a result, we noticed, while applying these categories to the two cases, that the boundaries of each category are not very clearly defined, and each of the categories is connected to the other categories by one subordinate term or another. For example, we acknowledge that a boundary object or scaffold can become a trace throughout a creative process, and that the first-person perspective is very closely related to social situatedness, and has influence on the dialogical system. While the paper at hand is not the correct venue to discuss all of the theoretical matter related to the categorization and the subordinate terms, we will dedicate future work to refining the (description of the) categories, and further develop this framework to design hybrid tools for participatory, embodied sensemaking.

\section{ACKNOWLEDGMENTS}

We thank Andreas Lindlbauer for his work on the \#CapIt system; Verena Fuchsberger, Susanna Vogel, Nathalia Campreguer França, Moritz Kubesch, and the reviewers, for their valuable feedback on (earlier versions of) this paper; and Jakub Sypniewski for his proofreading and editing efforts.

\section{REFERENCES}

[1] Christopher Andrews, Alex Endert, and Chris North. 2010. Space to Think: Large High-resolution Displays for Sensemaking. In Proceedings of the SIGCHI Conference on Human Factors in Computing Systems (CHI '10). ACM, New York, NY, USA, 55-64. https://doi.org/10.1145/1753326.1753336 tex.ids: andrewsSpaceThinkLarge2010a.

[2] Ernesto Arias, Hal Eden, Gerhard Fischer, Andrew Gorman, and Eric Scharff. 2000. Transcending the individual human mind - creating shared understanding through collaborative design. ACM Transactions on Computer-Human Interaction (TOCHI) 7, 1 (2000), 84-113. http://dl.acm.org/citation.cfm?id=345015

[3] Nicolai Brodersen Hansen, Peter Dalsgaard, and Kim Halskov. 2017. Design Tools and Materials in Creative Work. In Proceedings of the 2017 ACM Conference Companion Publication on Designing Interactive Systems. ACM, Edinburgh United Kingdom, 376-379. https://doi.org/10.1145/3064857.3064869

[4] Richard Buchanan. 1992. Wicked Problems in Design Thinking. Design Issues 8, 2 (1992), 5. https://doi.org/10.2307/1511637

[5] Andy Clark. 2001. Reasons, Robots and the Extended Mind. Mind \& Language 16, 2 (2001), 121-145. https://doi.org/10.1111/1468-0017.00162_eprint: https://onlinelibrary.wiley.com/doi/pdf/10.1111/1468-0017.00162.

[6] Nigel Cross. 1982. Designerly ways of knowing. Design Studies 3, 4 (1982), 221-227.

[7] Peter Dalsgaard. 2017. Instruments of Inquiry: Understanding the Nature and Role of Tools in Design. 11, 1 (2017), 13.

[8] Hanne De Jaegher. 2013. Embodiment and sense-making in autism. Frontiers in Integrative Neuroscience 7 (2013). https://doi.org/10.3389/fnint.2013.00015

[9] Hanne De Jaegher. 2016. Grasping intersubjectivity: an invitation to embody social interaction research. Phenomenology and the Cognitive Sciences 16 (2016), 491-523. 
[10] Hanne De Jaegher and Ezequiel Di Paolo. 2007. Participatory sense-making. Phenomenology and the Cognitive Sciences 6, 4 (Dec. 2007), 485-507. https: //doi.org/10.1007/s11097-007-9076-9

[11] Dries De Roeck, Pieter Jan Stappers, and Achiel Standaert. 2014. Gearing up! a designer-focused evaluation of ideation tools for connected products. In Proceedings of the 8th Nordic Conference on Human-Computer Interaction: Fun, Fast, Foundational (NordiCHI '14). Association for Computing Machinery, New York, NY, USA, 521-530. https://doi.org/10.1145/2639189.2639204

[12] Brenda Dervin. 1998. Sense-making theory and practice: an overview of user interests in knowledge seeking and use. fournal of Knowledge Management 2, 2 (Dec. 1998), 36-46. https://doi.org/10.1108/13673279810249369

[13] Laura Devendorf and Daniela K. Rosner. 2017. Beyond Hybrids: Metaphors and Margins in Design. In Proceedings of the 2017 Conference on Designing Interactive Systems. ACM, Edinburgh United Kingdom, 995-1000. https://doi.org/10.1145/ 3064663.3064705

[14] Alan Dix and Layda Gongora. 2011. Externalisation and design. In Procedings of the Second Conference on Creativity and Innovation in Design (DESIRE '11). Association for Computing Machinery, New York, NY, USA, 31-42. https://doi org/10.1145/2079216.2079220

[15] Ozgur Eris, Nikolas Martelaro, and Petra Badke-Schaube. 2014. A comparative analysis of multimodal communication during design sketching in co-located and distributed environments. 35, 6 (2014), 34

[16] Joep Frens and Bart Hengeveld. 2013. To Make is to Grasp. In 5th International Congress of International Association of Societies of Design Research. Tokyo, Japan. https://pure.tue.nl/ws/files/3908485/590447512073284.pdf

[17] Jonas Frich, Lindsay MacDonald Vermeulen, Christian Remy, Michael Mose Biskjaer, and Peter Dalsgaard. 2019. Mapping the Landscape of Creativity Support Tools in HCI. In Proceedings of the 2019 CHI Conference on Human Factors in Computing Systems. ACM, Glasgow Scotland Uk, 1-18. https://doi.org/10.1145/ 3290605.3300619

[18] Verena Fuchsberger. 2019. The future's hybrid nature. Interactions 26, 4 (June 2019), 26-31. https://doi.org/10.1145/3328481

[19] Gabriela Goldschmidt. 1994. On visual design thinking: the vis kids of architecture. Design Studies 15, 2 (April 1994), 158-174. https://doi.org/10.1016/0142-694X(94) 90022-1

[20] Connie Golsteijn, Elise van den Hoven, David Frohlich, and Abigail Sellen. 2014 Reflections on Craft Research for and Through Design. In Proceedings of the 8th Nordic Conference on Human-Computer Interaction: Fun, Fast, Foundational (NordiCHI '14). ACM, New York, NY, USA, 421-430. https://doi.org/10.1145/ 2639189.2639194

[21] Camilla Groth. 2017. Making sense through hands: design and craft practice analysed as embodied cognition. Ph.D. Dissertation. OCLC: 989751653.

[22] Emrecan Gulay and Andrés Lucero. 2019. Integrated Workflows: Generating Feedback Between Digital and Physical Realms. In Proceedings of the 2019 CHI Conference on Human Factors in Computing Systems. ACM, Glasgow Scotland Uk, 1-15. https://doi.org/10.1145/3290605.3300290

[23] Cornelius Herstatt and Birgit Verworn. 2004. The 'Fuzzy Front End' of Innovation. In Bringing Technology and Innovation into the Boardroom. Palgrave Macmillan UK, London, 347-372. https://doi.org/10.1057/9780230512771_16

[24] Caroline Hummels. 2016. Embodied Encounters Studio: A Tangible Platform for Sensemaking. In Proceedings of the 2016 CHI Conference Extended Abstracts on Human Factors in Computing Systems. ACM, San Jose California USA, 3691-3694. https://doi.org/10.1145/2851581.2890272

[25] Caroline Hummels and Jelle van Dijk. 2015. Seven Principles to Design for Embodied Sensemaking. ACM Press, 21-28. https://doi.org/10.1145/2677199. 2680577

[26] Nanna Inie and Peter Dalsgaard. 2020. How Interaction Designers Use Tools to Manage Ideas. ACM Transactions on Computer-Human Interaction 27, 2 (April 2020), 1-26. https://doi.org/10.1145/3365104

[27] Philémonne Jaasma. 2018. Exchanging perspectives: designing for public sphere. Ph.D. Dissertation. Technische Universiteit Eindhoven, Eindhoven. OCLC 8087212825.

[28] Philémonne Jaasma, Jelle van Dijk, Joep Frens, and Caroline Hummels. 2017. On the Role of External Representations in Designing for Participatory Sensemaking. Proceedings of the Conference on Design and Semantics of Form and Movement - Sense and Sensitivity, DeSForM 2017 (Oct. 2017). https://doi.org/10. 5772/intechopen.71207 Publisher: IntechOpen.

[29] Jennifer Jacobs and Leah Buechley. 2013. Codeable Objects: Computational Design and Digital Fabrication for Novice Programmers. In Proceedings of the SIGCHI Conference on Human Factors in Computing Systems (Paris, France) (CHI '13). Association for Computing Machinery, New York, NY, USA, 1589-1598. https://doi.org/10.1145/2470654.2466211

[30] Giulio Jacucci and Ina Wagner. 2007. Performative roles of materiality for collective creativity. In Proceedings of the 6th ACM SIGCHI conference on Creativity \& cognition - C\&C '07. ACM Press, Washington, DC, USA, 73. https: //doi.org/10.1145/1254960.1254971

[31] I. Jowers, M. Prats, S. Lim, A. McKay, S. Garner, and S. Chase. 2008. Supporting Reinterpretation in Computer-Aided Conceptual Design. In Proceedings of the
Fifth Eurographics Conference on Sketch-Based Interfaces and Modeling (Annecy, France) (SBM'08). Eurographics Association, Goslar, DEU, 151-158.

[32] Eija Kaasinen, Heli Väätäjä, Hannu Karvonen, and Yichen Lu. 2014. The fuzzy front end of experience design. In Proceedings of the 8th Nordic Conference on Human-Computer Interaction: Fun, Fast, Foundational. ACM, Helsinki Finland, 797-800. https://doi.org/10.1145/2639189.2654829

[33] David Kirsh. 2010. Thinking with external representations. AI \& SOCIETY 25, 4 (Nov. 2010), 441-454. https://doi.org/10.1007/s00146-010-0272-8

[34] David Kirsh and Paul Maglio. 1994. On Distinguishing Epistemic from Pragmatic Action. Cognitive Science 18, 4 (1994), 513-549. https://doi.org/10.1207/s15516709 $\operatorname{cog} 1804 \_1 \quad$ eprint: https://onlinelibrary.wiley.com/doi/pdf/10.1207/s15516709-og1804_1.

[35] Gary Klein, Brian Moon, and Robert R. Hoffman. 2006. Making Sense of Sensemaking 1: Alternative Perspectives. IEEE Intelligent Systems 21, 4 (July 2006), 70-73. https://doi.org/10.1109/MIS.2006.75

[36] Jon Kolko. 2011. Exposing the magic of design: a practitioner's guide to the methods and theory of synthesis. Oxford University Press, New York.

[37] Klaus Krippendorff. 1989. On the Essential Contexts of Artifacts or on the Proposition That "Design Is Making Sense (Of Things)". Design Issues 5, 2 (1989), 9-39. https://doi.org/10.2307/1511512 Publisher: The MIT Press.

[38] Joanna Kwiatkowska, Wiesław Bartkowski, Olga Górnicka, and David Lamas. 2015. Applying Generative Techniques to Avoid Technology Push Effect in Ideas and Prototypes Created by Technology-oriented People. In Proceedings of the Mulitimedia, Interaction, Design and Innnovation on ZZZ - MIDI '15. ACM Press, Warsaw, Poland, 1-9. https://doi.org/10.1145/2814464.2814480

[39] Jessica Lindblom and Tom Ziemke. 2003. Social Situatedness of Natural and Artificial Intelligence: Vygotsky and Beyond. Adaptive Behavior 11, 2 (June 2003), 79-96. https://doi.org/10.1177/10597123030112002 Publisher: SAGE Publications Ltd STM.

[40] Caroline Lundqvist, Daniel Klinkhammer, Kim Halskov, Stefan Paul Feyer, Jeanette Falk Olesen, Nanna Inie, Harald Reiterer, and Peter Dalsgaard. 2018. Physical, digital, and hybrid setups supporting card-based collaborative design ideation. In Proceedings of the 10th Nordic Conference on Human-Computer Interaction. ACM, Oslo Norway, 260-272. https://doi.org/10.1145/3240167.3240177

[41] Fiona Maciver and Julian Malins. 2016. Two Heads Are Better Than One: Principles for Collaborative Design Practice. In Collaboration in Creative Design: Methods and Tools, Panos Markopoulos, Jean-Bernard Martens, Julian Malins, Karin Coninx, and Aggelos Liapis (Eds.). Springer International Publishing, Cham, 13-31. https://doi.org/10.1007/978-3-319-29155-0_2

[42] Valérie Maquil and Eric Ras. 2012. Collaborative Problem Solving with Objects: Physical Aspects of a Tangible Tabletop in Technology-based Assessment. In From Research to Practice in the Design of Cooperative Systems: Results and Open Challenges, Julie Dugdale, Cédric Masclet, Maria Antonietta Grasso, Jean-François Boujut, and Parina Hassanaly (Eds.). Springer London, London, 153-166. https: //doi.org/10.1007/978-1-4471-4093-1_11

[43] Meredith Ringel Morris, Jarrod Lombardo, and Daniel Wigdor. 2010. WeSearch: Supporting Collaborative Search and Sensemaking on a Tabletop Display. In Proceedings of the 2010 ACM Conference on Computer Supported Cooperative Work (CSCW'10). ACM, New York, NY, USA, 401-410. https://doi.org/10.1145/1718918. 1718987

[44] Julien Nelson, Xavier Malon, and Nicolas Férey. 2019. Analyzing Interaction Dynamics at the Fuzzy Front-End of Innovation Projects: A Tool for Prospective Ergonomics. In Proceedings of the 20th Congress of the International Ergonomics Association (IEA 2018) (Advances in Intelligent Systems and Computing), Sebastiano Bagnara, Riccardo Tartaglia, Sara Albolino, Thomas Alexander, and Yushi Fujita (Eds.). Springer International Publishing, Cham, 1001-1007. https://doi.org/10. 1007/978-3-319-96071-5_102

[45] Sharoda Paul and Meredith Ringel Morris. 2011. Sensemaking in Collaborative Web Search. Human-Computer Interaction 26, 1 (Jan. 2011), 72-122. https: //doi.org/10.1080/07370024.2011.559410

[46] Dorian Peters, Lian Loke, and Naseem Ahmadpour. 2020. Toolkits, cards and games - a review of analogue tools for collaborative ideation. CoDesign 16, 1 (2020), 1-25. https://doi.org/10.1080/15710882.2020.1715444 Publisher: Taylor \& Francis_eprint: https://doi.org/10.1080/15710882.2020.1715444.

[47] Jörgen Sandberg and Haridimos Tsoukas. 2015. Making sense of the sensemaking perspective: Its constituents, limitations, and opportunities for further development: MAKING SENSE OF SENSEMAKING PERSPECTIVE. Journal of Organizational Behavior 36, S1 (Feb. 2015), S6-S32. https://doi.org/10.1002/job.1937

[48] Liz Sanders and George Simons. 2009. A Social Vision for Value Co-creation in Design. Open Source Business Resource December 2009 (2009). Place: Ottawa Publisher: Talent First Network.

[49] Donald A. Schön. 1983. The reflective practitioner: How professionals think in action. Vol. 5126. Basic books.

[50] Dorothé Smit, Thomas Grah, Martin Murer, Vincent van Rheden, and Manfred Tscheligi. 2018. MacroScope: First-Person Perspective in Physical Scale Models. In Proceedings of the Twelfth International Conference on Tangible, Embedded, and Embodied Interaction (TEI '18). ACM, New York, NY, USA, 253-259. https: //doi.org/10.1145/3173225.3173276 
[51] Dorothé Smit, Andreas Lindlbauer, Martin Murer, Bart Hengeveld, and Manfred Tscheligi. 2019. Let the Bot Take Care of It: Exploring \#CapIt, a Whiteboard Table Capture System. https://doi.org/10.18420/ecscw2019_ep16

[52] Dorothé Smit, Doenja Oogjes, Bruna Goveia de Rocha, Ambra Trotto, Yeup Hur, and Caroline Hummels. 2016. Ideating in Skills: Developing Tools for Embodied Co-Design. ACM Press, 78-85. https://doi.org/10.1145/2839462.2839497

[53] Sune Vork Steffensen. 2012. Care and conversing in dialogical systems. Language Sciences 34, 5 (Sept. 2012), 513-531. https://doi.org/10.1016/j.langsci.2012.03.008

[54] Erik Stolterman, Jamie McAtee, David Royer, and Selvan Thandapani. 2008 Designerly tools. In Proceedings of the Design Research Society Conference 2008 Sheffield, UK. http://shura.shu.ac.uk/drs2008/session10/track d/1

[55] Erik Stolterman and James Pierce. 2012. Design tools in practice: studying the designer-tool relationship in interaction design. In Proceedings of the Designing Interactive Systems Conference on - DIS '12. ACM Press, Newcastle Upon Tyne, United Kingdom, 25. https://doi.org/10.1145/2317956.2317961

[56] Lucy Suchman. 1987. Plans and Situated Actions: the Problem of Human-Machine Communication. Cambridge University Press, New York.

[57] Ambra Trotto and Caroline Hummels. 2013. Engage me, do!: engagement catalysers to ignite a (design) conversation. In Proceedings of the 6th International Conference on Designing Pleasurable Products and Interfaces - DPPI '13. ACM Press, Newcastle upon Tyne, United Kingdom, 136. https://doi.org/10.1145/2513506.2513521

[58] Ambra Trotto and Caroline Hummels. 2013. Nurturing Personal Engagemen in Design. In Proceedings of the 2013 International Design Research Conference. Tokyo, Japan, 13.

[59] Karthikeyan Umapathy. 2010. Requirements to support collaborative sensemaking. In CSCW CIS Workshop, Vol. 10.

[60] Rosa van der Veen, Jeroen Peeters, and Ambra Trotto. 2018. Charged Utopia VR: Exploring Embodied Sense-making in the Virtual Space. In Proceedings of the Twelfth International Conference on Tangible, Embedded, and Embodied Interaction Association for Computing Machinery, New York, NY, USA, 7.

[61] Jelle van Dijk. 2013. Creating traces, sharing insight: explorations in embodied cognition design. Ph.D. Dissertation. Eindhoven University of Technology, Eindhoven.

[62] Jelle van Dijk. 2018. Designing for Embodied Being-in-the-World: A Critical Analysis of the Concept of Embodiment in the Design of Hybrids. Multimodal Technologies and Interaction 2, 1 (Feb. 2018), 7. https://doi.org/10.3390/mti2010007

[63] Jelle van Dijk and Caroline Hummels. 2017. Designing for Embodied Being-inthe-World: Two Cases, Seven Principles and One Framework. ACM Press, 47-56. https://doi.org/10.1145/3024969.3025007

[64] Jelle van Dijk, Remko van der Lugt, and Caroline Hummels. 2014. Beyond distributed representation: embodied cognition design supporting sociosensorimotor couplings. ACM Press, 181-188. https://doi.org/10.1145/2540930. 2540934

[65] Jelle Van Dijk and Gerrit Willem Vos. 2011. Traces in creative spaces. In Proceedings of the 8th ACM conference on Creativity and cognition. ACM, 91-94. http://dl.acm.org/citation.cfm?id=2069634

[66] Jari Varsaluoma, Heli Väätäjä, Eija Kaasinen, Hannu Karvonen, and Yichen Lu. 2015. The Fuzzy Front End of Experience Design: Eliciting and Communicating Experience Goals. In Proceedings of the Annual Meeting of the Australian Special Interest Group for Computer Human Interaction. ACM, Parkville VIC Australia, 324-332. https://doi.org/10.1145/2838739.2838761

[67] Roberto Verganti. 2008. Design, Meanings, and Radical Innovation: A Metamodel and a Research Agenda*. Fournal of Product Innovation Management 25, 5 (2008), 436-456. https://doi.org/10.1111/j.1540-5885.2008.00313.x _eprint: https://onlinelibrary.wiley.com/doi/pdf/10.1111/j.1540-5885.2008.00313.x.

[68] James R. Wallace, Stacey D. Scott, and Carolyn G. MacGregor. 2013. Collaborative Sensemaking on a Digital Tabletop and Personal Tablets: Prioritization, Comparisons, and Tableaux. In Proceedings of the SIGCHI Conference on Human Factors in Computing Systems (CHI '13). ACM, New York, NY, USA, 3345-3354. https://doi.org/10.1145/2470654.2466458

[69] Christian Weichel, Jason Alexander, Abhijit Karnik, and Hans Gellersen. 2015. SPATA: Spatio-Tangible Tools for Fabrication-Aware Design. In Proceedings of the Ninth International Conference on Tangible, Embedded, and Embodied Interaction TEI '14. ACM Press, Stanford, California, USA, 189-196. https://doi.org/10.1145/ 2677199.2680576

[70] Robert E. Wendrich. 2013. The Creative Act Is Done on the Hybrid Machine. In DS 75-1: Proceedings of the 19th International Conference on Engineering Design. Seoul, Republic of Korea, 399-308.

[71] Paweł Wozniak, Nitesh Goyal, Przemysław Kucharski, Lars Lischke, Sven Mayer, and Morten Fjeld. 2016. RAMPARTS: Supporting Sensemaking with SpatiallyAware Mobile Interactions. In Proceedings of the 2016 CHI Conference on Human Factors in Computing Systems (CHI '16). ACM, New York, NY, USA, 2447-2460. https://doi.org/10.1145/2858036.2858491

[72] Albena Yaneva. 2005. Scaling Up and Down: Extraction Trials in Architectural Design. Social Studies of Science 35, 6 (Dec. 2005), 867-894. https://doi.org/10. 1177/0306312705053053 Publisher: SAGE Publications Ltd. 